\title{
APLICAÇÃO DE BACILLUS SUBTILIS NO CONTROLE DE NEMATOIDES DAS GALHAS EM TOMATEIRO
}

\author{
Lorrayne Guimarães Bavaresco $^{1}$, Fabio Fernando de Araujo ${ }^{2}$ \\ Universidade do Oeste Paulista - UNOESTE, Programa de Pós-Graduação em Agronomia, Presidente Prudente, SP. E- \\ mail: Igbavaresco@hotmail.com
}

\begin{abstract}
RESUMO
Os nematoides formadores das galhas causam sérios danos à cultura do tomateiro, prejudicando o desenvolvimento de plantas, devido ao comprometimento do sistema radicular. O objetivo deste trabalho foi avaliar o efeito da aplicação de Bacillus subtilis no controle de nematoides das galhas em tomateiro. O experimento foi conduzido em câmara de crescimento de plantas, utilizando solo naturalmente infestado por nematoides do gênero Meloidogyne. $O$ delineamento experimental foi inteiramente casualizado, com a utilização de dois cultivares de tomateiro e três tratamentos. Aos 40 dias após o transplante das mudas foram avaliados: altura de plantas, massa seca da parte aérea, massa fresca de raízes e contagem do número de formas ativas de nematoides e ovos nas raízes. Observou-se que a aplicação de Bacillus subtilis promoveu o aumento do sistema radicular e reduziu a população de nematoides das galhas em raiz de tomateiro suscetível.
\end{abstract}

Palavras-chave: Meloidogyne spp., rizobactéria, controle biológico.

\section{APPLICATION OF BACILLUS SUBTILIS ON THE CONTROL OF NEMATOIDES OF GALHAS TOMATOES}

\begin{abstract}
The root-knot nematodes cause serious damages to the tomato crop, hampering the development of plants, due to the compromising of the root system. The objective of this work was to evaluate the effect of the application of Bacillus subtilis on the control of root-knot nematodes in tomato. The experiment was conducted in a plant growth chamber, using soil naturally infested by nematodes of the genus Meloidogyne. The experimental design was completely randomized, using two tomato cultivars and three treatments. At 40 days after transplantation of the seedlings were evaluated: plant height, dry shoot mass, fresh root mass and counting of the number of active forms of nematodes and eggs in the roots. It was observed that the application of Bacillus subtilis promoted the increase of the root system and reduced the population of root-knot nematodes in susceptible tomato root.
\end{abstract}

Keywords: Meloidogyne spp., rhizobacteria, biological control. 


\section{INTRODUÇÃO}

Os fitonematoides são organismos que parasitam diferentes culturas, causando prejuízos econômicos em âmbito global que ultrapassam 150 bilhões de dólares por ano (ABAD et al., 2008). $\mathrm{O}$ parasitismo por nematoides das galhas, pertencente ao gênero Meloidogyne, são entre os principais problemas fitossanitários o de maior importância econômica a cultura do tomateiro, resultando em perdas de produtividade na ordem de 30 a 80\% (CHARCHAR, ARAGÃO, 2005).

Este grupo de fitonematoides são endoparasitos obrigatórios que penetram em raízes de plantas suscetíveis e estabelecem um sítio de alimentação, formando células nutridoras, hipertrofiadas que apresentam alta atividade metabólica, causando deformações no sistema radicular (FARIA et al. 2003; FERRAZ; MONTEIRO, 2011). O aumento da intensidade de infecção das raízes reduz a taxa de absorção e translocação de água e nutrientes, limitando o crescimento da planta, provocando amarelecimento das folhas, murchamento, redução de produtividade e até mesmo o colapso de plantas em áreas severamente infestadas.

Além dos danos causados, estes fitonematoides são altamente prolíferos, apresentando ciclo de vida rápido, com ampla distribuição geográfica e grande diversidade de hospedeiros, dificultando a sua prevenção e controle no solo. (FREITAS et al., 2001). Por estas razões, medidas integradas de controle são essenciais para redução de populações no solo a níveis abaixo de danos econômicos, já que a sua erradicação em áreas infestadas se torna praticamente impossível (VAZ et al.2011).

O controle biológico, com a utilização de rizobactérias, tem-se apresentado como uma alternativa eficiente e ecologicamente sustentável para a supressão de fitonematoides no solo, sendo de fácil aplicação, de baixo custo econômico e mínimo impacto ambiental, quando comparado a outros métodos de controle (VAZ et al.2011).

A proteção de plantas tem sido relacionada a combinação de múltiplos mecanismos de ação por estes microrganismos na região da rizosfera promovendo o antagonismo, competição por espaço e nutrientes, antibiose, parasitismo, produção de enzimas e indução de resistência da planta hospedeira. O objetivo deste trabalho foi avaliar o efeito da aplicação de Bacillus subtilis no controle de nematoides das galhas em tomateiro.

\section{METODOLOGIA}

O experimento foi conduzido em câmara de crescimento de plantas (Fitotron) no laboratório de Microbiologia do solo da Faculdade de Ciências Agrárias, da Universidade do Oeste Paulista, Presidente Prudente - SP. O solo utilizado foi coletado em Presidente Prudente - SP $\left(22^{\circ} 09^{\prime} 21.2^{\prime \prime} \mathrm{S}, \quad 51^{\circ} 26^{\prime} 40.6^{\prime \prime} \mathrm{W}\right)$, em área naturalmente infestada por nematoides do gênero Meloidogyne, com densidade populacional de 480 formas ativas de Meloidogyne e 320 ovos de nematoides por $100 \mathrm{~g}$ de solo, determinada pela técnica descrita por Jenkins (1964).

$\mathrm{O}$ delineamento experimental foi inteiramente casualizado, em arranjo fatorial $2 \mathrm{x}$ 3, sendo avaliados dois cultivares de tomateiro Katia e BS DI0038 (suscetível e resistente aos nematoides das galhas, respectivamente) e três tratamentos: testemunha, inoculação de $B$. subtilis nas mudas e inoculação de $B$. subtilis no solo, com seis repetições, contendo uma planta por vaso. As mudas de tomateiro foram transplantadas aos 35 dias após a semeadura, para vasos de polietileno com capacidade de $2 \mathrm{~L}$.

Para os tratamentos com inoculação da rizobactéria foi utilizado o isolado de Bacillus subtilis (AP-3), com concentração da solução bacteriana aproximada em 5,0 x $10^{8} \mathrm{UFC}^{-1}$ (unidades formadoras de colônias), determinada pelo método de diluição seriada em placas. Foram aplicados 0,005 mL da solução bacteriana muda ${ }^{-1}, 24$ horas antes do transplante, e para inoculação no solo foram aplicados $2 \mathrm{~mL}$ da solução bacteriana vaso ${ }^{-1}$, em volta do caule da planta num raio de $5 \mathrm{~cm}$, no momento do transplante das mudas. 
Aos 40 dias após o transplante foram avaliados: altura de plantas, massa seca da parte aérea, massa fresca de raízes e contagem do número de formas ativas e ovos de nematoides nas raízes. A parte aérea foi separada do sistema radicular e seca em estufa com circulação forçada de ar a $60^{\circ} \mathrm{C}$, até atingir peso constante. As raízes frescas foram cuidadosamente lavadas, secas em papel toalha, pesadas e submetidas a procedimentos de trituração, peneiramento e extração de formas ativas e ovos de nematoides de acordo coma técnica de Coolen e D'Herde (1972).

Os dados foram submetidos a análise de variância e as médias foram comparadas pelo teste de Tukey ao nível de $5 \%$ de probabilidade.

\section{RESULTADOS}

Não houve interação significativa entre os cultivares e os métodos de aplicação para altura de plantas, massa seca da parte aérea e ovos $\mathrm{g}^{-1}$ de raiz. Comparando-se os cultivares, o cultivar Katia obteve os maiores valores médios para as variáveis altura de plantas e massa fresca da parte aérea. No entanto, verificou-se que o controle de ovos no solo foi mais efetivo quando utilizado o cultivar BS DI0038 (Tabela 1).

Tabela 1. Efeito da aplicação de Bacillus subtilis sobre a altura de plantas, massa seca da parte aérea e ovos $\mathrm{g}^{-1}$ de raiz em cultivares de tomateiro, cultivado em solo naturalmente infestado por nematoides do gênero Meloidogyne, em câmara de crescimento de plantas.

\begin{tabular}{|c|c|c|c|}
\hline Cultivares & $\begin{array}{l}\text { Altura de plantas } \\
(\mathrm{cm})\end{array}$ & $\begin{array}{c}\text { Massa seca da parte } \\
\text { aérea }(\mathrm{g})\end{array}$ & Ovos $\mathrm{g}^{-1}$ de raiz \\
\hline Katia & $33,02 \mathrm{~A}$ & $2,5 \mathrm{~A}$ & $2057,62 b$ \\
\hline BS DI0038 & $25,36 \mathrm{~B}$ & $1,89 \mathrm{~B}$ & 1281,14 a \\
\hline $\mathrm{F}$ & $44,58 * *$ & $11,61 * *$ & $6,61^{*}$ \\
\hline \multicolumn{4}{|l|}{ Tratamentos } \\
\hline Testemunha & $29,35 \mathrm{~A}$ & $2,19 \mathrm{~A}$ & 1390,55 a \\
\hline B. subtilis nas mudas & $28,44 \quad A$ & $2,13 \mathrm{~A}$ & 2230,54 a \\
\hline B. subtilis no solo & 29,78 A & $2,28 \mathrm{~A}$ & 1387,04 a \\
\hline $\mathrm{F}$ & $0,47^{\text {ns }}$ & $0,24^{\mathrm{ns}}$ & $3,45^{*}$ \\
\hline CV (\%) & 11,78 & 24,41 & 54,28 \\
\hline
\end{tabular}

Médias seguidas pelas mesmas letras minúsculas nas colunas e maiúsculas nas linhas, não diferem estatisticamente pelo teste de Tukey. ${ }^{* *}$ Significativo a $1 \%$ de probabilidade, ${ }^{*}$ significativo a $5 \%$ de probabilidade e ns não significativo.

A aplicação do $B$. subtilis proporcionou efeito significativo para o crescimento do sistema radicular e redução de nematoides das galhas nas raízes do tomateiro cultivar Katia. Quando inoculado na muda, o isolado bacteriano aumentou em $70 \%$ a massa fresca radicular e reduziu 33,19\% o número de formas ativas de nematoides nas raízes, em relação à testemunha. Em solo inoculado estes valores foram ainda mais favoráveis ao desenvolvimento da planta apresentando $118 \%$ e 64,01\%, respectivamente (Tabela 2). Com relação ao cultivar BS DI0038, resistente aos nematoides das galhas, as inoculações de $B$. subtilis testadas não proporcionaram efeitos significativos adicionais no volume da matéria fresca radicular e redução de formas ativas de nematoides nas raízes em relação a testemunha. 
Tabela 2. Efeito da aplicação de Bacillus subtilis sobre o crescimento radicular e número de nematoides nas raízes em cultivares de tomateiro, cultivado em solo naturalmente infestado por nematoides do gênero Meloidogyne, em câmara de crescimento de plantas.

\begin{tabular}{lccccc}
\hline \multirow{2}{*}{ Tratamentos } & \multicolumn{2}{c}{ Katia } & \multicolumn{2}{c}{ BS DI0038 } & \multicolumn{2}{c}{ Katia } & \multicolumn{2}{c}{ BS DI0038 } \\
\cline { 2 - 7 } Testemunha & \multicolumn{2}{c}{ Massa fresca radicular (g) } & \multicolumn{2}{c}{ Formas ativas g de raiz } \\
B. subtilis nas mudas & $2,48 \mathrm{bA}$ & $1,38 \mathrm{aB}$ & 813,03 bA & 598,09 aA \\
B. subtilis no solo & $4,22 \mathrm{aA}$ & $1,22 \mathrm{aB}$ & 543,23 abA & 694,96 aA \\
\hline F & $5,41 \mathrm{aA}$ & $1,89 \mathrm{aB}$ & 292,63 aA & 533,75 aA \\
\hline CV (\%) & \multicolumn{3}{c}{$6,02^{* *}$} & \multicolumn{3}{c}{$3,47^{*}$} \\
\hline
\end{tabular}

Médias seguidas pelas mesmas letras minúsculas nas colunas e maiúsculas nas linhas, não diferem estatisticamente pelo teste de Tukey. ${ }^{* *}$ Significativo a $1 \%$ de probabilidade, ${ }^{*}$ significativo a $5 \%$ de probabilidade.

\section{DISCUSSÃO}

A utilização de Bacillus subtilis tem demostrado efeitos positivos na promoção do crescimento de plantas e expressivo potencial para o controle de fitonematoides, por meio da produção de compostos tóxicos, alteração de exsudatos radiculares e indução de mecanismos de defesa da planta hospedeira, reduzindo a invasão e reprodução dos nematoides nas raízes das plantas (FREITAS et al., 2005; ARAÚJO; MARCHESI, 2009).

Estudos demonstram que a presença de $B$ subtilis na rizosfera induz a degradação de exsudatos radiculares, interferindo a orientação dos nematoides, não permitindo o reconhecimento do estímulo quimiotrópico emitido pelas raízes, reduzindo a migração dos nematoides em direção ao sistema radicular, beneficiando o desenvolvimento vegetal pela inibição do parasitismo (ARAÚJO et al.,2002; ARAÚJO; MARCHESI 2009). Anita et al., (2006) corroboram com estes autores, salientando que plantas de tomateiro tratadas com $B$. subtilis apresentam maior resistência aos nematoides.

Voss (2013) ao avaliar diferentes doses de $B$. subtilis no controle de nematoides das galhas em tomateiro, verificou resultados semelhantes a este trabalho, não encontrando diferença significativa em relação ao crescimento da parte aérea das plantas, porém resultados significativos foram observados na redução do número de nematoides no solo, quando inoculado $3 \mathrm{ml}$ da solução bacteriana por vaso. Em estudo realizado por Vaz et al. (2011), também não houve diferenças significativas para a massa da parte aérea das plantas e redução de ovos quando aplicando o B. subtilis em sementes de tomateiro.

Violante e Portugal (2007) obtiveram uma melhora do sistema radicular de plantas de tomate com a inoculação de $B$. subtilis, sendo que o comprimento da raiz chegou a um aumento de $15 \%$ e a massa das raízes aumentaram até $26 \%$. De acordo com Kilian et al. (2000) essa bactéria é capaz de colonizar as raízes das plantas, formando um biofilme ao redor da raiz, podendo produzir metabólitos que estimulam os fitormônios vegetais e a solubilização e mobilização de nutrientes no solo, induzindo o crescimento das raízes e promovendo o melhor desenvolvimento de plantas.

\section{CONCLUSÃO}

A aplicação de Bacillus subtilis promoveu o aumento do sistema radicular e reduziu a população de nematoides das galhas em raiz de tomateiro suscetível. 


\section{REFERÊNCIAS}

ABAD, $P$ et al. Genome sequence of the metazoan plant-parasitic nematode Meloidogyne incognita. Natural Biotechnology, v. 26, n.8, 909- 915 p. 2008.

ANITA, B., G. Rajendran, and R. Samiyappan, 2006. Defense mechanism in tomato treated with Pseudomonas fluorescens against Meloidogyne incognita (Kofoid and White) Chitwood. Pest Management in Horticultural Ecosystems 12:63- 66.

ARAÚJO, F. F. et al. Influência de Bacillus subtilis na eclosão, orientação e infecção de Heterodera glycines em soja. Ciência Rural, Santa Maria, v. 32, n. 2, p. 197-203, 2002. https://doi.org/10.1590/S0103-84782002000200003

ARAÚJO, F. F.; MARCHESI, G. V. P. Uso de Bacillus subtilis no controle da meloidoginose e na promoção do crescimento do tomateiro. Ciência Rural, Santa Maria, v. 39, n. 5, p. 1558-1561, 2009. https://doi.org/10.1590/S0103-84782009000500039

CHARCHAR J. M; ARAGÃO F. A. S. Reprodução de Meloidogyne spp. em cultivares de tomate e pepino sob estufa plástica e campo. Nematologia Brasileira. v.29, p. 243-249, 2005.

COOLEN, W.A. \& C.J. D'HERDE. 1972. A Method for the Quantitative Extraction of Nematodes from Plant Tissue. State Nematology an Entomology Research Station, Ghent, 77 p.

FARIA, C. M. D. R. et al. Mecanismos de ataque e defesa na interação nematóide-planta. Revisão Anual de Patologia de Plantas (RAPP) v. 11, 373 p. 2003 . Disponível em:< http://docentes.esalq.usp.br/sbn/rapp/rapp08.pdf>. Data de acesso:07 jul. 2016

FERRAZ, L. C. C. B.; MONTEIRO, A. R. Nematoides In.: Amorim, L.; Rezende, J. A. M.; Bergamim Filho, A. Manual de fitopatologia: Princípios e conceitos. 4 ed. Piracicaba: Agronômica Ceres, 277289 p., 2011.

FREITAS, L. G.; et al. Introdução à nematologia. Viçosa: UFV, 2001. 84 p.

FREITAS, L. G.; et al. Isolamento e seleção de rizobactérias para controle de nematoides formadores de galhas (Meloidogyne spp.) na cultura do tomateiro. Nematologia Brasileira, v. 29 (2) 215-220 p. 2005.

JENKINS, J. A. The origen of the cultivated tomato. Ec. Bot. n. 2, 379-392, 1948.

KILIAN, M.; et al. FZB24 Bacillus subtilis mode of action of a microbial agent enhancing plant vitality. Pflan-zenschutz Nachrichten Bayer, v1. p. 72-93. 2000.

VAZ, M. V. et al. Controle biológico de Meloidogyne javanica e Meloidogyne incognita com Bacillus subtilis. Revista do Núcleo Interdisciplinar de Pesquisa e Extensão. Patos de Minas: UNIPAM, n. 8, vol. 1, 203-212 p., jul. 2011.

VIOLANTE, H. G. M.; PORTUGAL, V. O. Alteration of tomato fruit quality by root inoculation with plant growth-promoting rhizobacteria (PGPR): Bacillus subtilis BEB-13bs. Scientia Horticulturae, v. 113. p. 103-106. 2007. https://doi.org/10.1016/j.scienta.2007.01.031 
VOSS, G. B. Produção de Bacillus subtilis em biorreatores airlift e sua aplicação no controle de nematoide de galhas do tomateiro. Dissertação (mestrado) - Universidade Federal de Santa Catarina, Florianópolis, SC, 2013.

$115 p$. 